\title{
The Importance of a Stable Home and Family Environment in the Prevention of Youth Offending in South Africa
}

\author{
Thozama Mandisa Lutya*
}

\author{
Department of Social Work and Criminology, Faculty of Humanities, University of Pretoria, Cnr Lynwood and \\ Roper Streets, Hatfield Campus, Pretoria, Gauteng Province, South Africa
}

\begin{abstract}
The importance of a stable home and family environment in the prevention of youth offending in South Africa.
This paper aims to present a strategy to prevent youth offending in South Africa. The strategy is motivated by research findings obtained from the study titled "Home and family circumstances of young offenders: A social worker's view" in 2007. The findings of this study revealed that socio-economic factors; inept parenting and socialisation practices; exposure to inter-parental violence; sibling criminality; negative parent-child relationship; parental response to deviant behaviour of the child as well as the lack of parental interest in the rehabilitation programmes offered to their offending children increases the likelihood of a child partaking in criminal activities. This paper argues that in order to prevent youth offending South Africa should consider the importance of a stable home and family environment in the prevention of youth offending. Firstly, family planning is important. Secondly, parental involvement in a child's activities is vital to ensure proper supervision and monitoring. Thirdly, in the absence of adequate parenting skills, efficacy and management parenting programmes could help parents learn a conforming manner of rearing their children. Lastly, once they have been caught committing a crime parents ought to take centre stage to ensure that the child's behavioural transformation takes place.
\end{abstract}

Keywords: Family stability, youth offending, parenting, crime prevention.

\section{INTRODUCTION}

The basic assumption of the research was that unstable home and family circumstances contribute to young offending. Two questions need to be asked in order to understand the impact of unstable home and family circumstances in the upbringing of children. Firstly, which factors within South African homes contribute to young offending? Jantjies and Popovac (2011) point out that lack of parental involvement in children's activities and parental rejection are key variables within the South African home and family settings contributing to young offending. In addition, Hayes (2007) describes parent child communication deficiencies contributing to young offending as parent's poor interpretation of child's behaviour as well as child misunderstanding of parental motives. The authors suggest re-education of parents and children about each other's behaviours and intention. Hall (2011) has identified overcrowding as a major problem in the development of behavioural problems amongst South African children. Hall reports that a small dwelling housing adults and school going children is not conducive for proper learning: sexual abuse might occur if parents and children share beds. According to Hall (2011) in 2010 4, 3 million out of the 18,6 million South African children lived in overcrowded

*Address corresponding to this author at the Department of Social Work and Criminology, Faculty of Humanities, University of Pretoria, Cnr Lynwood and Roper Streets, Hatfield Campus, Pretoria, Gauteng Province, South Africa; Tel: 012420 5906; Fax: 012420 2093; E-mail: Thozama.lutya@up.ac.za households. About $33 \%$ of African children live in overcrowded households with large family members in informal dwellings (Hall 2011; Hall and Chennells 2011).

Secondly, why do some children attach significance and replicate dysfunctional circumstances witnessed in unstable home and family environments whilst others do not? Dysfunctional behaviour is often displayed by authority figures that children trust: especially if that behaviour is not sanctioned or punished. Utilising Albert Bandura's social learning theory to explain behaviour modelling, Isom (1998) explains that parental aggression is likely to be replicated by children: children may express modelled parental behaviour during the process of interacting with other children. Furthermore, children rarely question parental behaviour: they are likely to copy and replicate it without interrogation. On the other hand some children may not repeat destructive parental behaviour. Biological theorist suggests that other factors such as autonomic nervous system, heart rate, increase blood pressure, nausea and fainting matter (Isom 1998). These factors block a person's ability to learn behaviour. That means for children who might experience fainting spells or increased blood pressure at seeing their parents engage in dysfunctional behaviour, learning such behaviour might not settle.

Thirdly, the South African youth are faced with a variety of conflicting experiences daily and early in their lives. If not direct victims of abuse, they witness 
parental conflict and at times, if not suffering at the hands of a sibling, they become part of sibling's criminal activities (Centre for Justice and Crime Prevention: CJCP 2009). CJCP (2009) reports that about $48.9 \%$ of South African children reside in households where violence is used as a strategy to resolve conflict. The CJCP study illustrates that these children witness family members hitting each other when angry, argue a lot, use physical punishment to discipline children, or children witness parents or family members intentionally hitting one another. Furthermore, the media to which they are exposed and peers with whom they associate condone the violence occurring at home by either replicating it through play or films and videos (Alboukordi, Nazari, Nouri and Sangdeh 2012; Bialobrzeska, Randell, Helmann and Winkler 2009). In the meanwhile the environments occupied by most young offenders are riddled with violence in the form of gangsters, drug dealers and the proliferation of guns and other dangerous weapons (Leoschut and Burton 2009; Standing 2005). At school, they either become victims at the hands of other learners, or become perpetrators of crime (Van der Merwe 2010). Some school learners are victimised by educators such as teachers and school principals (Burton 2008).

Fourth, family poverty and unemployment, child orphans, large family structures and commercial sexual exploitation are amongst the challenges facing children in South Africa. Family poverty and unemployment have a direct impact on the parenting styles and practices (Asher 2006; Weatherburn and Lind 1998). Most parents spend a significant amount of time either looking and searching for work or travelling to and from work (Lutya 2007). That means they spend little time supervising and monitoring their children. During parental absence, children may get involved in wayward behaviour which could bring them to the attention of criminal justice authorities (Lutya 2007). Once the parents are alerted to their children's criminal activities, instead of resolving matters amicably, they become angry and disappointed with their children (Lutya 2007). The social workers and probation officers informed me that some parents yell, punish harshly or reject children once they get arrested. Youth offending could be a sign of inept parenting. Furthermore, the lack of parental financial resources to provide for the family motivate some children to become part of exploitative labour practices such as commercial sexual exploitation. At times in the quest to obtain material goods (Leclerc-Madlala 2003), South African children are used by adults to commit crime (Frank and Muntingh 2006). In addition, adolescent girls such as those orphaned and poverty stricken are able to obtain material goods through intergenerational sex (sexual activities with older men) (Leclerc-Madlala 2003). It is during such relationships that most of them contract sexually transmitted diseases. Another important factor is that there could be a correlation between teenage pregnancies and family poverty. Holborn and Eddy (2011) have revealed that $51 \%$ of $15-24$ year olds persons are unemployed. In addition the authors point out that the pregnancy rate for this age group is $58 \%$. It is important to realise that teenage pregnancies contribute to the increase in the number of children within household requiring financial services. Teenage mothers are without resources, which mean that most of them reside with their biological parents who may assist with the upbringing of the grandchild. It could be difficult for a teenager to focus on educational studies with a baby at hand (Morrell, Bhana and Shefer 2012). Subsequently the teenage mother has limited opportunities of getting employment. With poverty and parental unemployment prevalent in most homes, children of teenage mothers become part of the financial hardships.

\section{YOUTH CRIME PREVENTION}

There are three levels at which youth offending is prevented in South Africa: primary, secondary and tertiary levels. Primary crime prevention programmes include: situational and developmental crime prevention as well as police patrols and crime awareness workshops; secondary crime prevention consists of media awareness programmes and school related programmes. Some youth wilderness programmes also exist but are accessible to a few young South Africans residing in urban areas. They are likely to be accessed by most young person's expressing risky behaviours. At a tertiary level, other than law enforcement and other criminal justice activities responding to crime, rehabilitation and reintegration programmes are implemented in some correctional centres.

\subsection{Gaps in Youth Crime Prevention}

The location of the targeted group, parenting context, and understanding of the factors contributing to crime as well as perceptions and attitudes towards crime prevention are some of the aspects creating gaps in the prevention of youth crime in South Africa. The distance between the programmes and young 
persons determine the usefulness of crime prevention and control in South Africa. High contingents of South African programmes are located in urban areas and are not accessible to youth located in rural areas. Irrespective of the quality of content and the dedication of facilitators to crime prevention if programmes cannot be accessed by the needed groups, that could render them ineffective. Furthermore, the context within which South African children are parented provides challenges to any professional aiming to implement a parenting programme in this country. As mentioned earlier, work commitments, time spent searching for employment opportunities as well as the growing number of child headed households suggests that certain children could be growing up with little access to their parents (Lutya 2007). That means the activities of parentless children are not monitored and supervised. In this situation, it could be difficult for parent-child interaction and parent-child communication to properly take effect. The proliferation of child headed households owing to parental death through HIV/Aids illnesses and other natural and unnatural death causes forces older siblings to assume roles of caregivers to younger siblings (Meintjes, Hall, Marera and Boulle 2009). Out of a total of 18.2 million children in South Africa 122000 are heading households (Meintjes et al. 2009). The age range of child-headers is from 14 years and older (Meintjes et al. 2009). Although supported by government and other service organisations through grants, the amount they currently receive is not enough to ensure that they deliver adequate parenting practices and styles. Moreover, parenting can be a sensitive matter that should be addressed with a caring consideration.

The most complicated point about parenting in this country is that, South Africa comprises of diverse cultures whose parenting practices and styles are informed by their social, political and economic situations. The values and norms instilled on children are determined by a set of experiences confronting parents at the time. For example, certain South African parents cannot afford to reject material goods obtained through criminal activities brought home by their offspring. Doing so could mean loss of livelihood. In essence what is considered as crime prevention by one community can be considered as a constraint by the other community owing to the diverse understanding of the causes of crime and crime prevention and control. Besides, in some communities parents do not think their parenting styles and practices directly contribute to crime. They see crime prevention and control as the primary responsibility of the police.

\section{STABLE HOME AND FAMILY ENVIRONMENT}

Based on the research findings as well as in consideration of the gaps in South African youth crime prevention strategies, the author suggests that crime prevention policy makers should put emphasis on family planning, parenting programmes and parental involvement in children's activities. Combined together these strategies will not only prevent crime but will contribute towards financial growth of families. The families can only give birth to the children they can afford. The fewer children the better chances of attending to their needs and activities. In this manner they will be able to attain knowledge of their activities, peers and educational progress. Prior giving birth parents could access support, education and knowledge regarding the manner in which they should approach parenting.

\subsection{Family Planning}

People in general, with specific consideration of single women and female children, should be encouraged to consistently make use of family planning strategies to control birth in order to reduce the number of children born. Parents with a lesser number of children are might be able to supervise and monitor their children closely. They have time to ensure that they attend to the needs of each child. As pointed out by Loayza (2007) family planning could be an effective strategy in the reduction of crime. Loayza (2007) explains that most unwanted children are likely to engage in crime which could lead to a life of misery such as correctional confinement. Unwanted children are likely to be left to their own devices, unsupervised and non-monitored.

Family planning is important for women because gender role stereotypes influence women to think that they should primarily rear and socialise children. In Frank and Muntingh (2006) about $40.2 \%$ of the interviewed 541 young suspects in secure care facilities (awaiting trial detention centres) were living with the mother prior arrest. Young suspects were detained for allegedly committing economic crimes such as robbery and housebreaking. The offspring becomes a primary responsibility of the mother regardless of the role played by the father in caring for the child. When the father desert the family, the worst case scenario, the financial needs of the child rests with the mother. As a single parent presumably with other children depending on her, parenting and socialisation of the children with work commitments 
Table 1: Statistics of Sentenced and Un-Sentenced Children Under the Age of 18

\begin{tabular}{|c|c|c|c|}
\hline \multicolumn{2}{|c|}{ Sentenced and un-sentenced children under the of age of 18 } \\
\hline Crime categories & Un-sentenced & Sentenced & Total \\
\hline \hline Economical & 81 & 148 & 378 \\
\hline Aggressive & 139 & 239 & 198 \\
\hline Sexual & 61 & 137 & 8 \\
\hline Narcotics & 5 & 3 & 33 \\
\hline Other & 19 & 541 & 846 \\
\hline Total & 305 & & \\
\hline
\end{tabular}

Source: Departmental of Correctional Service (2011/2012).

becomes a difficult task to accomplish. Inadequate parenting and socialisation contribute directly to the development of youth misbehaviour.

The statistics in Tables 1 and $\mathbf{2}$ illustrate the number of sentenced and un-sentenced children and youth in South African Correctional Centres for the period 2011 to 2012. It appears that young offenders commit aggressive and economical crimes more than sexual, narcotics and other crimes. The reason could be that South Africa is dominated by the culture of violence, materialism and a sense of entitlement (Bruce 2008). In addition children are likely to be used by adults in the perpetration of violent economical crimes such as housebreaking, car-hijacking as well as business robbery (Frank and Muntingh 2006). During the process of their use adults encourage children to use the extreme forms of violence in order to achieve criminal goals (Frank and Muntingh 2006). After the crime has been committed successfully children get rewards and compliments that encourage them to commit more crime.

The child respondents in Frank and Muntingh (2006) gave the following statements as responses of adults to children after the successful perpetration of crime: "they shake your hand and say you are a man"; "he makes you feel like a real criminal"; "they tell you 'you are a dog', they make you happy and excited"; "He says: he is not scared, he is a big man, he is my brave man", (Frank and Muntingh 2006). Clearly, a 14 year old child with no positive role models whose parents do not care about his involvement in criminal activities might be encouraged and motivated by these words. When asked what their parents say about their involvement in criminal activities the respondents overwhelmingly said "mothers protect them when they do things"; "families and parents accept stolen goods they do not ask where they come from"; "kids see that when they bring stuff parents are happy when they come home with stolen goods, children become happy to see the approval and acknowledgement of their parents", (Frank and Muntingh 2006). Apparently, in this study the child respondents intimated that parents make them feel guilty for not bringing money home and force them to go on the streets to get money or food (Frank and Muntingh 2006). The concept of going to the streets to seek money is called Ukuphanda: a Nguni word meaning to seek money or food as a means of survival. On return from the streets with either money or food parents highly appreciate the effort.

Table 2: Statistics of Sentenced and Un-Sentenced Youth Between the Ages of 18 and 25

\begin{tabular}{|c|c|c|c|}
\hline \multicolumn{3}{|c|}{ Sentenced and un-sentenced youth between the ages of 18 and 25 } \\
\hline Crime categories & Un-sentenced & Sentenced & Total \\
\hline \hline Economical & 7215 & 9146 & 26948 \\
\hline Aggressive & 11156 & 15792 & 6994 \\
\hline Sexual & 2831 & 4163 & 1272 \\
\hline Narcotics & 644 & 628 & 2436 \\
\hline Other & 943 & 1493 & 54011 \\
\hline Total & 22789 & 31222 & \\
\hline
\end{tabular}

Source: Department of Correctional Services (2011/2012). 


\subsection{Inept Parenting}

Parenting is inept if parents fail to communicate, interact, supervise, guide and monitor children's activities. Families do not exist alone: they are surrounded by neighbours, schools, religious institutions, diverse ethnicities and language groupings (Burton 2008). The location of the parents is important to ensure the performance of adequate parenting practices. Freiberg, Homel and Lamb (2007) suggest that parents who are not connected to supportive networks are least likely to provide good quality parenting. Freiberg et al. (2007) have pointed out that good quality parenting and family stability rests upon "external forces and characteristics of the social, cultural and economic environments within which the family lives". Furthermore, the lifestyles and routine activities of others within the neighbourhoods impact negatively or positively towards the parenting practices and styles of parents. Adequate parenting in crowded environments riddled with violence and crime, likely neighbourhoods of young offenders, is difficult to achieve. Adversities such as stressed, depressed and preoccupied families are least likely to provide nurturing and stimulation in their home environments: that impedes the development of mother-child attachment (Freiberg et al. 2007). In violent neighbourhoods dominated by gangs, gun culture and criminal activities, parents are likely to apply strict parenting styles as the way of constraining their children from becoming gang members. Although this may not be the correct way of rearing children, some parents may regard peaceful measures such as negotiating, communicating and interacting with their children too lenient to apply in violence dominated neighbourhoods. Instead of keeping children at home, the strict parenting practices may drive them away, especially male children, and thus run the risk of seeking love and a sense of belonging from peer and delinquent groups such as gangs.

\subsection{Adequate Socialisation}

Family planning results in few children being born in families. Parents, single or married are able to rear their children adequately to prevent the development of a criminal personality. The socialisation practices are adequate: parents are able to discipline their children adequately without resorting to strict measures such as harsh physical punishment. Essentially, family planning will prevent the adherence to traditional customs encouraging most women and men to give birth with limited or few financial resources.

\subsection{Parental Involvement in Children's Activities}

If parents have few children to socialise, it means all of them may receive the required attention. Parents might be able to attend to their extra-mural and schooling activities. There is a vital need for South African parenting adults to supervise and monitor children's activities. Substance abuse among adolescents has increased. The age of introduction to alcohol usage is younger than 13 years old (Ramsoomar and Morojele 2012). School violence in South Africa has increased dramatically in the last five years: learners bring dangerous weapons to school; some young female children are even scared to attend school due to their experiences of sexual violence at the hands of educators and co-male learners (Burton 2008). In a nationwide study on school violence conducted by Burton in 2008 educators reported feeling safe but narrated incidences of violence levelled at educators by learners. In Burton (2008) educators reported that learner violence is exacerbated by the increase availability and use of substances such as drugs and alcohol. School educators also do not escape the aggression of young learners.

When not involved in violence or abusing substances they play truant to gamble informally on the streets or formally in gambling establishments. The literature review conducted by Moseki (2004) has revealed that 2738 out of 69908 were identified as truant by the educators. If parents are involved closely in their children's lives, they are in a position to attain knowledge of their activities during and after school. Although there is a difference between deviant behaviour of children and criminal activities, research evidence suggests that if left unmitigated deviant behaviour is likely to progress to delinquency. Nevertheless, children from small families get involved in mischievous activities. Owing to the amount of children at home, parents with few children can observe early if the child is expressing wayward behaviour and tackle it immediately. It is possible that some parents can observe such behaviours but considers them as part of adolescent behaviour that will fade with time.

\subsection{Parenting Programmes}

Parenting programmes are important to educate, train and support parents to attain skills in selfmanagement, management of children's behavioural problems, conflict resolution, communication and interaction with children, emotional support of children 
as well as responsible and accountable reaction to children's wayward behaviour. That means parents are educated and trained to coordinate their daily tasks to suit the needs of their children's activities, supervision, communication, interaction and monitoring. If children express wayward behavioural tendencies, parents are taught peaceful strategies to manage such behaviour without resorting to stringent measures that could create conflict with the offspring. Instead of taking things personally they learn a responsible and accountable manner of resolving conflict: emotionally supporting their children instead of harshly punishing them. If conflict arises, the lessons obtained from the parenting programme covering parent-child open communication and interaction will steer parents and children towards peaceful conflict resolution strategies.

\subsection{Rehabilitation of a Youth Offender}

Traumatic early childhood experiences could result in the development of a child's delinquent personality during adolescent years. In the absence of parents to carefully constrain these behavioural expressions, adolescent deviant behaviour may progress to delinquency. Once parents are alerted to these behaviours by criminal justice authorities, they take things personally instead of finding adequate ways of resolving conflict. However, if they participate meaningfully in rehabilitation programmes aimed at transforming their children's offending behaviour they are able to learn about the contribution of certain home and family circumstances to children's participation in criminal activities. In this manner, family relationships and parent-child relationships are enhanced and strengthened.

\section{CONCLUSION}

This paper has presented a strategy to prevent youth offending in South Africa. The strategy is based on the research findings the author obtained from interviewing social workers and probation officers regarding their views on factors contributing to youth offending in South Africa. In addition the literature review concurs with the fact that dysfunctional family circumstances drive children into crime. Therefore to prevent youth offending prior its occurrence, a stable home and family environment is important. Parenting can be a daunting task that does not come with a manual on the manner in which children should be socialisation. Therefore, parenting support is needed where parents are not aware of mechanisms of socialising children peacefully. However, once the child has committed the crime, parental participation in the rehabilitation process of child should be encouraged.

\section{REFERENCES}

Alboukordi, Sajad, Nazari, Ali.M, Nouri, Robabeh and Sangdeh, Khodadadi. J. 2012. "Predictive factors for juvenile delinquency: The role of family structure, parental monitoring and delinquent peers." International Journal of Criminology and Sociological Theory 5(1): 770-777.

Asher, Jeff. A. 2006. "Exploring the relationship between parenting styles and juvenile delinquency". MA Thesis, Department of Family Studies and Social Work, Miami University, Oxford, Ohio.

Bialobrzeska, Maryla, Randell, Christina, Liora, Hellmann and Gisela, Winkler. 2009. Creating a Caring School: A guide for school management Teams. Braamfontein: South African Institute for Distance Education.

Burton, Patric. 2008. Merchants, skollies and stones: Experiences of school violence in South Africa. Claremont, Cape Town: Centre for Justice and Crime Prevention.

Centre for Justice and Crime Prevention (CJCP). 2009. Building youth resilience to crime and violence. Claremont, Cape Town: CJCP.

Dawes, Andrew, De Sas Kropiwnicki, Zosa, Kafaar, Zuhayr and Richter, Linda. 2005. Corporal punishment of children: A South African national survey. Cape Town: Human Sciences Research Council.

Denning, Rebecca and Homel, Ross. 2007. "The challenges of turning developmental theory into meaningful policy and practice". Pp.298-318 in Pathways and Crime Prevention: Theory, policy and practice, edited by France A. Homel R. Devon: Willan Publishing

Frank, Cheryl and Muntingh, Lucas. 2006. Children used by adults to commit crime: children's perceptions of their use by adults in the commission of crime. Children's Rights Project: University of the Western Cape.

Freiberg, Kate, Homel, Ross and Lamb, Cherie. 2007. "The pervasive impact of poverty on children: tackling adversity and promoting child development through pathways to Prevention project". Pp. 226-246 in Pathways and Crime Prevention: Theory, policy and practice. Devon: Willan Publishing.

Gallinetti, Jacqui, Kassan, Dashka and Sloth-Nielsen, Julia. 2006. Children used by adults to commit crime: situational analysis and pilot design, Children's Rights Centre: University of the Western Cape.

Hall, Katherine. 2011. Statistics on children in South Africa: Housing and services - overcrowding. University of Cape Town: Children's Institute.

Hall, Katherine and Chennells, Matt. 2011. Children and income poverty: A brief update. University of Cape Town: Children's Institute.

Hayes, Alan. "Why early life is not enough: timing and sustainability in prevention and early intervention". Pp. 202-220 in Pathways and Crime Prevention: Theory, policy and practice edited by France A, Homel R. Devon: Willan Publishing.

Holborn, Lucy and Eddy, Gail. 2011. First Step to healing the South African family. Braamfontein: South African Institute of Race Relations.

Isom, Margaret. D. 1998. Albert Bandura: The social learning theory. Retrieved July 25, 2012 (http//www.criminology.fsu.edu/crimtheory/bandura.htm)

Jantjies, Janine and Popovac, Masa. 2007.Gender dynamics and girls' perceptions of crime and violence. Centre for Justice and Crime Prevention, Claremont, Cape Town. 
Leclerc-Madlala, Susan. 2003. "Transactional Sex and the Pursuit of Modernity". Social Dynamics: A journal of African Studies 29 (2):213-233.

Leoschut, Lezanne. 2006. The influence of family and community violence exposure on victimisation rates of South African youth. Claremont, Cape Town: CJCP.

Leoschut, Lezanne and Burton, Patric. 2009. Building Resilience to Crime and Violence in Young South Africans. Claremont, Cape Town: CJCP.

Loayza, Norman.V. 2007. "Preventing violence: Long run crime prevention policies". Thinking of Violence, Winter 2007-2008 Revista 9.

Lutya, Thozama. M. 2007. "Home and family circumstances of young offenders: A social workers view". British Journal of Community Justice 5 (3): 63-80.

Moran, Patricia and Ghate, Deborah. 2005. "The effectiveness of parenting support". Children and Society, 19: 329-336. http://dx.doi.org/10.1002/chi.878

Morrell, Robert, Bhana, Deevia and Shefer, Tamara. 2012. Books and Babies: Pregnancy and young children at school. Cape Town: Human Sciences Research Council Press.
Moseki, Monkie.M. 2004. The nature of truancy and the life world of truants in secondary schools. MED Dissertation, University of South Africa, Pretoria.

Pelser, Eric. 2008. Learning to be lost: Youth crime in South Africa. Discussion Paper for the Youth Policy Initiative, May 13; Reserve Bank, Pretoria.

Ramsoomar, Leane and Norojele, Neo. K. 2012. 'Trends in alcohol prevalence, age of initiation and association with alcohol related harm among South African youth: Implications for policy'. South African Medical Journal 5 (7): 609-612.

Standing, Johnny. 2005. The threat of gangs and anti-gangs policy: Policy discussion paper. ISS Paper 116.

Van der Merwe, Nicola. 2009. "A quantitative study on the proviolence attitudes among learners in South Africa". Acta Criminologica : Criminological and Victimological Society of Southern Africa (Crimsa) 2009 Conference Special Edition (1): 107-125.

Weatherburn, Don and Lind Bronwyn. 1998. Poverty, Parenting, Peers and crime prone neighbourhoods. Canberra: Australian Institute of Criminology.

\section{DOI: http://dx.doi.org/10.6000/1929-4409.2012.01.8}

(C) 2012 Thozama Mandisa Lutya; Licensee Lifescience Global.

This is an open access article licensed under the terms of the Creative Commons Attribution Non-Commercial License (http://creativecommons.org/licenses/by-nc/3.0/) which permits unrestricted, non-commercial use, distribution and reproduction in any medium, provided the work is properly cited. 